be a level of awareness of the problem of mental illness and substance abuse caused by domestic violence, there is no evidence, in New Zealand, of a constructive response to this from the services that women access. The documentary is part of a teaching resource that consists of handouts and a power point presentation (contained on a CD) and a booklet that explains how to use the teaching resource.

\title{
1008 HE DROVE ME MAD - A DRAMATISED DOCUMENTARY ABOUT DOMESTIC VIOLENCE AND MENTAL ILLNESS
}

Homeworks Trust. A voluntary organisation who advocate for specialist women only services and housing - including refuges for women with mental health and drug and alcohol problems as a result of domestic violence Correspondence to Homeworks Trust, P.O. Box 20710 Glen Eden, Waitakere City 0604, New Zealand

\subsection{6/ip.2010.029215.1008}

The dramatised documentary He Drove Me Mad is designed to help voluntary, statutory and non-governmental organisation service providers understand and assist women trapped by domestic violence and mental illness/substance abuse. It provides strategies to assist agencies to support women in ways that enable them to take action and begin the process of recovery. The documentary presents the viewers with: dramatised experiences of women who have been abused and who are mentally unwell or drunk attempting to get help. The dramatisations are generalised scenarios, taken from real life situations, demonstrating a number of the barriers that women in this situation encounter when trying to access help information about domestic violence and mental illness, the size and scope of the problem in New Zealand and how agencies can constructively help these women when they encounter them. The script was developed with the guidance of women who have been driven mad by domestic violence and who understand how difficult it is to get information, to find others who understand their predicament, and to access services that respond in a constructive, non-abusive way. Raising awareness of these women's predicament and providing constructive agency responses can potentially free women from lives of violence and abuse, break the process of inter-generational abuse, contribute to the elimination of violence against women and promote peaceful homes and communities. While there may 